\title{
NA ESTEIRA DE E.P.THOMPSON: RELAÇÕES SOCIAIS DE GÊNERO E O FAZER-SE AGENTE COMUNITÁRIA DE SAÚDE NO MUNICÍPIO DO RIO DE JANEIRO
}

\author{
IN WAKE OF E.P.THOMPSON: SOCIAL GENDER RELATIONS AND MAKING YOURSELF A HEALTH \\ COMMUNITY AGENT IN THE CITY OF RIO DE JANEIRO
}

\author{
EN EL CAMINO DE E.P.THOMPSON: RELACIONES SOCIALES DE GÉNERO Y EL FORMARSE AGENTE \\ COMUNITARIA DE SALUD EN EL MUNICIPIO DE RÍO DE JANEIRO
}

\author{
Anna Violeta Ribeiro Durão ${ }^{1}$ \\ Clarissa Alves Fernandes de Menezes ${ }^{2}$
}

Resumo Este artigo resultou de uma pesquisa que teve como objetivo analisar a institucionalização do trabalho das agentes comunitárias de saúde no município do Rio de Janeiro, mediante a avaliação de como uma perspectiva de gênero presente na política de qualificação dessas trabalhadoras vem afetando a constituição de sua profissão. Participaram do estudo 167 agentes entre os anos 2011 e 2013. Apresenta-se, primeiramente, a perspectiva de gênero presente nas políticas do Estado direcionadas às agentes. Em seguida, recupera-se a experiência de trabalho dessas trabalhadoras na implantação do Programa Saúde da Família no município e a sua relação com habilidades vistas como inatas à condição feminina, para depois se analisar como a reforma da atenção primária realizada pela Secretaria Municipal de Saúde e Defesa Civil em 2009 vem afetando o processo de trabalho das agentes. Constatou-se que, com as novas formas de gestão adotadas, as agentes vêm se distanciando das comunidades atendidas, perdendo, desta maneira, o diferencial que dava significado e reconhecimento ao seu trabalho.

Palavras-chave agentes comunitárias de saúde; gênero; trabalho.

\begin{abstract}
This article is the outcome of a research project carried out aiming to analyze the institutionalization of the work of community health agents in the city of Rio de Janeiro, the capital of the state of Rio de Janeiro, Brazil, by evaluating how a gender perspective present in these workers' qualification policy has affected how the profession is formed. A total of 167 agents took part of the study between 2011 and 2013. First, the gender perspective present in this State's policies directed to the agents is presented. The work experience of these workers in the implementation of the Family Health Program in the city and its relation to the skills seen as innate to the female condition are analyzed, followed by an investigation of how the primary care reform undertaken by the $\mathrm{Mu}-$ nicipal Health and Civil Defense Department in 2009 has affected the agents' work process. It was found that with the new types of management adopted, the agents have been distancing themselves from the communities they serve, thus losing the unique features that gave meaning and brought recognition to their work. Keywords community health agents; genre; work.
\end{abstract}




\section{Introdução}

Este artigo analisa a institucionalização do trabalho das agentes comunitárias de saúde (ACSs) no município do Rio de Janeiro, buscando avaliar como uma perspectiva de gênero presente na política de qualificação dessas trabalhadoras vem afetando a constituição da sua profissão. Optou-se por colocar em relevo, no decorrer do texto, como o próprio título indica, o fazer-se das agentes durante a sua trajetória de trabalho como forma de dar voz a essas mulheres que participaram ativamente na implantação do Programa Saúde da Família (PSF) no município.

O 'fazer-se' foi um termo utilizado pelo historiador britânico Edward Palmer Thompson para salientar o processo de constituição da classe operária inglesa nos anos 1780 a 1830. Ele buscava perceber em suas análises a relação entre o modo de produção e a consciência social, recuperando as experiências históricas construídas por homens e mulheres no embate entre classes. Assim, distanciava-se de uma visão anti-histórica que entende classe como categoria estrutural e acentuava a luta, tentando compreender como visões antagônicas de mundo se contrapunham ou alinhavavam na concretude do real (Mattos, 2012). Para o autor, classe é, fundamentalmente, uma relação histórica que "precisa estar sempre encarnada em pessoas e contextos reais" (Thompson, 1987, p. 10).

Para tanto, Thompson trabalha com o conceito de experiência como forma de mediação entre o ser social e a consciência social, destacando que, embora as pessoas nasçam em determinado modo de produção, são sujeitos ativos da história. Assim, o conceito de experiência apresenta uma dupla face: a experiência vivida e a experiência percebida (Mattos, 2012). Thompson esclarece:

(...) como pessoas que experimentam suas situações e relações produtivas determinadas como necessidades e interesses e como antagonismo, e em seguida 'tratam' essa experiência em sua consciência e sua cultura (as duas outras expressões excluídas pela prática teórica) das mais complexas maneiras (sim, 'relativamente autônomas') e em seguida (muitas vezes, mas nem sempre, através de estruturas de classe resultantes) agem, por sua vez, sobre sua situação determinada (Thompson, 1981, p. 182, grifo do autor).

Thompson sinaliza, dessa maneira, que não se pode pensar o ser social desarticulado dos elementos da cultura hegemônica de um determinado modo de produção, mas que na luta pela satisfação das necessidades de sua existência há numerosas formas de valores e culturas próprios que são intrínsecos ao modo de vida dos trabalhadores.

Diante das transformações que ocorreram no mundo do trabalho nas últimas décadas, as quais tiveram como consequência a subtração de direitos 
duramente conquistados pela classe trabalhadora, o autor instiga a análise sobre como os trabalhadores vêm pensando e vivendo essas mudanças, bem como sobre as formas de conformação e resistência com que experimentam a exploração da sua força de trabalho.

Assim, tendo em mente o conceito de experiência em Thompson (1981), procura-se analisar a institucionalização do trabalho das ACSs no Rio de Janeiro, considerando-se as normas e regras consolidadas nas políticas e as formas como essas mulheres têm vivenciado a precarização do trabalho, assim como as formas de lutas travadas para a sua efetiva profissionalização. Ao se privilegiar a construção histórica dessas profissionais, buscou-se o afastamento de uma visão essencialista do que é ser mulher presente na política e de análises que compreendem a qualificação como uma relação linear entre formação e posto de trabalho. ${ }^{3}$ Vale a pena acrescentar que as agentes vivenciam o mesmo processo de qualificação relacionado ao trabalho do cuidado e da assistência, em que habilidades construídas no espaço doméstico são entendidas como vocação e, portanto, não reconhecidas socialmente, sendo significativas de formas precárias de inserção no mercado de trabalho (Simões Barbosa et al., 2012).

\section{Caminhos da pesquisa}

Este artigo origina-se da pesquisa intitulada "Processo de qualificação de trabalhadores técnicos em saúde: aspectos da qualificação profissional no SUS", realizada pela Escola Politécnica de Saúde Joaquim Venâncio (EPSJV) de 2010 a 2012, cujo objetivo era identificar e analisar os movimentos de conformação de alguns grupos profissionais inseridos no setor saúde, dentre eles o das agentes comunitárias de saúde (ACSs). ${ }^{4} \mathrm{Na}$ pesquisa com grupo das ACSs analisou-se como a perspectiva de gênero se relacionava com a sua qualificação.

Os dados desta pesquisa foram obtidos por meio da literatura pertinente ao tema e da aplicação e análise de um questionário fechado, respondido por 167 agentes comunitários de saúde do PSF do município do Rio de Janeiro que compunham as turmas da formação técnica desenvolvida pela EPSJV em parceria com a Prefeitura do Rio de Janeiro entre 2011 e 2013. Traçou-se o perfil socioeconômico, os percursos formativos e as trajetórias profissionais dessas ACSs. Por meio da análise desses questionários, selecionaram-se 16 trabalhadoras, com as quais foram feitas entrevistas qualitativas. Optou-se por entrevistar agentes que apresentassem trajetórias educacionais e profissionais diversas e que fossem representativas das diferentes regiões do município que a pesquisa abrangia.

A maioria das entrevistadas tinha em média mais de oito anos como ACS. Eram, portanto, profissionais antigas no PSF. Assim, sobrelevaram-se, 
nas falas, as transformações que vinham ocorrendo no seu trabalho, a partir da reforma da atenção primária, as quais tinham impacto tanto no conteúdo quanto na forma de sua atuação. $\mathrm{O}$ artigo traz, fundamentalmente, a análise dessas entrevistas.

Todas as ACSs que participaram das entrevistas foram informadas sobre o propósito da pesquisa e assinaram o termo de consentimento. O estudo foi aprovado pelo Comitê de Ética em Pesquisa da Escola Politécnica de Saúde Joaquim Venâncio, sob o nº CAAE 0052.0.408.000-112011/0168.

\section{A esfera doméstica como lócus do feminino}

Em diferentes modos de produção, observa-se a divisão sexual do trabalho, na qual a atividade das mulheres foi vinculada à esfera privada ou doméstica. Desse modo, ficou a cargo das mulheres a responsabilidade pela manutenção da vida imediata, pela alimentação de sua família, reprodução, cuidados e educação dos filhos, vestimentas, organização do lar etc.

No modo de produção capitalista, perpetua-se essa divisão, conjuntamente com os mecanismos ideológicos da classe dominante. Essa anterior subordinação das mulheres é apropriada e utilizada pelo capital visando não só ampliar a exploração do trabalho - fonte de riqueza - como também utilizar essa histórica subordinação para reduzir os custos dos capitalistas no processo de produção e reprodução do capital (Menezes, 2011).

Várias análises no campo da sociologia do trabalho estruturaram-se enfatizando os trabalhadores fabris do sexo masculino, deixando à margem o trabalho feminino. Na maioria das vezes, este era compreendido fora do âmbito da produção, ressaltando-se o papel da mulher no âmbito doméstico como fator importante para a recuperação e reprodução da força de trabalho. Vale lembrar a parcialidade desse entendimento, já que as mulheres, dependendo do momento histórico, estiveram presentes na produção em maior ou menor quantidade.

Hirata e Kergoat (2007) esclarecem que tais discussões passaram a ganhar corpo na França na década de 1970, quando o conceito de divisão sexual do trabalho foi posto em pauta pela sociologia. A princípio, os estudos sobre essa separação tinham como principal objetivo analisar a diferença entre homens e mulheres no mercado. A partir dos movimentos feministas, começou-se a querer dar visibilidade ao trabalho realizado pelas mulheres no espaço doméstico. As autoras assinalam que a ambição do movimento feminista era incorporar ao conceito de trabalho uma dimensão laboral que, "em nome da natureza, do amor e do dever materno" (Hirata e Kergoat, 2007, p. 597), passava despercebida - tanto pelos estudiosos da área quanto pela sociedade. 
A institucionalização do trabalho das ACSs é exemplar desse processo, pois se recorreu a um trabalho realizado pelas mulheres no espaço doméstico para disseminar a política do Estado. Não por acaso, conforme a lei n. 11.350/2006, é necessário para exercer a profissão ser moradora da área onde irá atuar. Tal dimensão de gênero presente na política acabou trazendo entraves para a sua efetiva profissionalização. Acrescente-se ainda que esse enfoque é transversalizado por uma questão de classe que marca o diferencial da política não só para as ACSs como também para a população-alvo da Estratégia Saúde da Família (ESF), ${ }^{5}$ pois a política não foi dirigida a qualquer mulher, mas a mulheres da mesma posição de classe do seu entorno.

A seguir, recupera-se um pouco da política de institucionalização do trabalho das agentes no Brasil, colocando em relevo o projeto da sua qualificação - no dizer de Gramsci (2001), pelo alto, ou seja, pelo Estado em sentido estrito. 6

\section{A institucionalização da profissão construída pelo alto - quando ser ACS é igual a ser mulher}

A institucionalização do trabalho das agentes foi gestada no princípio da década de 1990, momento histórico no qual se lutava para a construção do Sistema Único de Saúde (SUS), ao mesmo tempo que as políticas neoliberais ganhavam corpo no Brasil.

Por um lado, a contratação dessas mulheres é percebida como uma possibilidade de maior participação da população na política de saúde, rompendo com o poder biomédico centrado na doença. Por outro, com a restrição do Estado nas políticas, o trabalho dessas mulheres passa a ser compreendido como possibilidade de se aproveitar mão de obra barata que serviria para assegurar condições mínimas de saúde para o restante da população. Ao que tudo indica, essas políticas somam-se às políticas mais amplas que tinham como o foco as mulheres e as viam como potencializadoras de políticas públicas, em razão do papel de cuidadoras e educadoras que desempenhavam na família (Farah, 2004; Simões Barbosa, 2001).

A primeira política estatal envolvendo essas trabalhadoras ocorreu em 1987 no Ceará, onde se recrutaram 6.113 mulheres. Os critérios de seleção se resumiam a ser pobre, dona de casa, sem marido e, principalmente, ter reconhecimento da comunidade a que pertencia (Nogueira, Silva e Ramos, 2000).

Foi a partir de 1991, com a criação do Programa Nacional dos Agentes Comunitários de Saúde (PNACS), 7 que o trabalho dos agentes passou a fazer parte de uma política mais ampla de Estado. A princípio, a implantação ocorreu no Nordeste, onde mais uma vez contrataram-se mulheres para disseminar 
cuidados caseiros para diminuir determinadas doenças, sobretudo a mortalidade materno-infantil (Tomáz, 2002; Morosini, 2010). Scott (2011), ao analisar a implantação do Programa Saúde da Família (1994) no Nordeste, assinala que na incorporação das agentes houve uma sutil mudança no enfoque do programa, pois a ênfase dada inicialmente à participação comunitária deslocou-se para a família. A autora critica esse deslocamento, destacando que no ideário da política constroem-se imagens de famílias que se sobrepõem ao esforço de se entender, articuladamente, gênero, geração e família. Como vários autores (Rizzotto, 2000; Montaño, 2003; Simões Barbosa et al., 2012) sublinham, essa ênfase na família vem sendo fomentada atualmente como forma de compensar a diminuição do papel do Estado nas políticas sociais.

O conceito de comunidade8 foi se modificando na implementação do PSF, passando a significar um espaço limitado da implantação da política, o qual pode ser entendido como uma família ampliada - em que a mulher, em razão do seu papel no cuidado, socialmente construído como um atributo feminino, é usada para disseminar a política de Estado. Nesse contexto, ser da comunidade acaba por restringir o trabalho das ACSs não mais ao espaço doméstico, mas a um lócus bem delimitado de atuação: as microáreas onde moram e trabalham.

Nesse movimento, uma dimensão da vida que era entendida como não trabalho vai ganhando uma dimensão pública. Esse deslocamento teve uma consequência contraditória no trabalho das agentes, pois ao mesmo tempo que seu trabalho ganhou visibilidade e certo reconhecimento social, a relação do trabalho com a esfera doméstica refletiu-se na precarização das relações de trabalho, que se davam sem nenhuma garantia de estabilidade, com baixos salários e diversos tipos informais de contratos.

Durante o governo de Fernando Henrique Cardoso (1994-1998/1998-2002), no bojo da reforma do Estado, em que se celebram as parcerias governamentais com a sociedade civil, ganha ênfase na qualificação das agentes o caráter sui generis do seu trabalho (Morosini, 2010; Durão, Morosini e Carvalho, 2011). As principais características da trabalhadora sui generis eram o pendor à ajuda solidária e o seu pertencimento à comunidade. Nota-se, portanto, uma dimensão não manifesta da política que naturaliza o fazer das agentes, enaltecendo capacidades há muito concebidas como o lugar da mulher cuidadora. Na área da saúde, a divisão sexual do trabalho consolidou-se sob uma forte hierarquia profissional, em que o tratar distanciou-se do cuidar. Fonseca (apud Simões Barbosa, 2001, p. 104) sinaliza que 'o tratar', atributo dos médicos, se caracteriza por uma postura técnica e distanciada do paciente, enquanto " $\mathrm{O}$ 'cuidar', associado ao trabalho doméstico feminino, traz implícitas qualidades como abnegação, disponibilidade, delicadeza e honestidade no lidar com o paciente". 
Pode-se dizer que houve na história da profissionalização dessas trabalhadoras, no dizer de Bourdieu (2010), a construção do arbitrário cultural em natural, ou ainda uma naturalização da história. Em grande medida, essa naturalização se deu a partir de uma visão dos formuladores da política de determinada concepção de família, na qual a posição hierarquizada e subalternizada da mulher está bem delimitada.

\section{O fazer-se ACS no município do Rio de Janeiro}

As ACSs que fizeram parte da pesquisa ingressaram como agentes entre 1999 e 2008, momento em que passa a ganhar corpo, no município do Rio de Janeiro, o PSF (1999). Conforme a avaliação do secretário de Saúde do estado do Rio de Janeiro na época, Gilson Cantarino O'Dayer (1999-2002), o PSF no estado encontrava-se estagnado, havendo a necessidade de se ampliar a rede básica e promover a integralidade do sistema (Serra, 2003). Vale acrescentar que, a partir do ano 2000, o Ministério da Saúde e o Banco Mundial passam a alocar recursos para expansão do PSF nos grandes centros urbanos (Fonseca, 2013).

A cidade do Rio de Janeiro vem sendo caracterizada como a cidade partida, onde a cisão favela/asfalto marca a intervenção distinta do Estado no espaço urbano. Nessa clivagem, a favela passou a estar diretamente relacionada a classes sociais empobrecidas, com pouca qualidade de vida e, nas últimas décadas, como local dominado pelo tráfico.

Nesse contexto, como assinala Morosini (2001, p. 13), tanto a expansão do PACS quanto a do PSF criaram novos desafios para as ACSs, pois elas tiveram que lidar com "a violência urbana, o tráfico e o consumo de drogas, as questões relativas à saúde mental, o estresse, entre outros". Considere-se ainda que as áreas privilegiadas para a implantação do programa foram locais considerados de risco à saúde, com grande concentração populacional. Para tanto, selecionaram-se ACSs que atendessem a determinadas qualidades, entre as quais se destacava a exigência de que residissem há mais de dois anos na comunidade onde iriam atuar e que tivessem sensibilidade com o estado de saúde da localidade (Morosini, 2001).

Constatou-se que as ACSs entrevistadas eram moradoras do seu local de atuação, o que permitiu maior facilidade de acesso às áreas de risco, vale dizer, a entrada nos territórios sob o domínio do tráfico, como também a promoção da saúde das pessoas consideradas como grupos de risco (hipertensos, diabéticos, tuberculosos, entre outros) que ficaram sob o controle do tráfico.

Na perspectiva das agentes, a possibilidade de estar perto de casa apresentava-se como uma possibilidade de conjugar o trabalho com o cuidado 
dos filhos e ainda diminuir o tempo gasto com o transporte. Em pesquisa anterior com as agentes, Simões Barbosa e colaboradores (2012) destacam que a possibilidade de estar perto dos filhos foi um dos principais argumentos das ACSs para justificarem a sua permanência no trabalho, mesmo em situações precárias. Os dados desta pesquisa confirmam a posição das autoras, pois esse foi um argumento recorrente quando perguntadas sobre o porquê da mudança de emprego. Como relata uma das entrevistadas:

Aí eu falei: não quero essa vida mais, porque você tem um filho e você não vê o filho se desenvolver. Aí o filho depende de ficar em creche, depende de pessoas, você está pagando pessoas para buscar o filho na creche. Aí eu falei: não quero mais essa vida (ACS 1).

Para efeito da implantação do PSF, o fato de a ACS ser mulher facilitava a entrada nas casas das pessoas e propiciava melhor aceitação, por parte dos moradores, da interferência do Estado - considerando que durante anos foram poucos os projetos de intervenção pública nessas comunidades e, quando existentes, caracterizavam-se como medidas pontuais, em momentos políticos específicos, na perspectiva de compra de votos.

As agentes tornam-se fundamentais para divulgar a proposta do programa, como também para romper com a desconfiança da população quanto à interferência direta do Estado. Como bem destaca uma entrevistada:

Nós passamos por muitos obstáculos. A gente batia nas portas e nem todo mundo abria a porta pra te atender. (...) batemos numa porta, veio um senhor e disse assim: "Pode cair fora daqui, porque eu já descobri que vocês são olheiros da Prefeitura" (ACS 12).

Além dessas dificuldades, tinham que lidar com o poder do tráfico nos territórios. Não por acaso o acesso das equipes de saúde nesses locais se deu e ainda se dá com a mediação dos agentes. Como apontam Georges e Santos (2012), os conflitos com a população local passam a ser mediados por mulheres da própria localidade, tornando-se, nesse sentido, um elemento de pacificação social.

Eu acho que é muito importante conhecer a comunidade com a palma da mão, principalmente em relação a esse negócio do tráfico, porque eles sabem quem é morador ou quem não é (ACS 4).

Ao contrário do que pressupunha a política, dentre as ACSs entrevistadas, embora fossem moradoras da comunidade, poucas tinham um trabalho anterior no território, ou relataram alguma experiência com trabalho em 
saúde ou prestação de cuidados pessoais. Seus itinerários profissionais eram extensos e erráticos, como os da maioria dos trabalhadores brasileiros que ocupam a mesma condição de classe das entrevistadas. Não só boa parte delas começou a trabalhar muito cedo como também suas trajetórias profissionais não eram pautadas por projeto anterior que lhes desse coerência (Durão et al., 2013).

Pode-se inferir que a experiência de trabalho dentro da comunidade era um fator a mais para a contratação, mas não o determinante. Além de uma prova de conhecimentos básicos de matemática e português, foram realizadas entrevistas nas quais se valorizavam, segundo as ACSs depoentes, articulação no discurso e perfil de liderança, entre outras habilidades. Observou-se que um dos critérios recorrentes que influenciaram a contratação era ter boa fluência verbal e capacidade de comunicação.

Eu acho que dentro da comunidade eles esperam que as pessoas se expressem mal; acho que eles já têm um estigma todo da comunidade, do falar mal no sentido de falar muita gíria, não saber se expressar direito, e assim, quando eu percebi, a entrevista já tinha acabado. (...) Acabou e ela falou: "Você fala tão bem que não parece que mora na comunidade", e eu fiquei com aquilo na cabeça (ACS 5).

Não por acaso, embora para a entrada no programa não fosse necessário o ensino médio completo e até 2002 só era necessário saber ler e escrever, ${ }^{9}$ as entrevistadas, em sua maioria, já tinham esse nível de ensino antes de ser tornar ACS. Esse aspecto pode estar relacionado tanto ao aumento da escolaridade no país (Rummert, 2009) quanto ao maior acesso à educação nos centros urbanos. Além disso, pode ser um indicador da preferência, mesmo que não explícita na política, por mulheres com maior grau de instrução. Carneiro (2013) ressalta que, atualmente, no município do Rio de Janeiro, algumas organizações sociais de saúde (OSSs) já estão exigindo o ensino médio na contratação das ACSs. Vale acrescentar que 36,5\% das entrevistadas também tinham outra formação técnica e 19\% estavam cursando ou já haviam cursado o ensino superior (Durão et al., 2013).

Os trabalhos realizados nas esferas não diretamente produtivas, tais como a saúde e a educação, são menos normatizados do que o trabalho industrial, pois em grande medida são mais dependentes do trabalho vivo. 10 Acrescente-se que carregam consigo uma dimensão de trabalho socialmente útil, ainda mais fortemente presente quando inseridos na esfera pública.

Também não por acaso, as políticas de qualificação das ACSs colocam peso nas habilidades construídas na esfera doméstica como forma de mediar tanto o afastamento efetivo do Estado nas políticas públicas quanto o distanciamento dos profissionais da saúde em relação à população. Nesse sentido, essas mulheres, que foram socialmente educadas a conceber a tarefa 
de cuidar como de sua responsabilidade, ao se verem engajadas com os problemas do seu entorno se sentem compelidas a atuar de forma mais orgânica junto à população. Acrescente-se que os problemas que afetam a população não diferem das experiências que elas vivenciam.

Embora haja a retomada de uma dimensão do cuidado, é no desempenho do próprio trabalho que as agentes tecem uma rede de pertencimento com os moradores e são reconhecidas pelo que fazem. Como expressa uma das entrevistadas:

Então, eu acho que mudou o meu olhar com relação à comunidade. Porque é muito diferente você estar na comunidade e você ser da comunidade. Até então eu estava na comunidade e aí passei a ser da comunidade, que é um pouco diferente. (...) O ser é porque você acaba se identificando com aquela população e você pensa: embora eu esteja aqui, eu tenho a minha casa e a minha vida. Embora a minha vida seja diferente da dela em alguns aspectos, eu acho que vou ter a possibilidade de fazer alguma coisa diferente (ACS 5).

Molinier (2012), ao analisar a ética no trabalho do cuidado,11 destaca os estudos de Galerand e Kergoat que constataram o envolvimento dessas trabalhadoras com o que fazem, mesmo tendo pouco reconhecimento social. Ressalta Molinier (2012) que o valor do trabalho, no sentido ético do termo, não é conferido de fora; depende da importância que ele adquire para o sujeito em razão de um tecido de experiências não restritas ao trabalho assalariado.

Embora o engajamento com o trabalho de ACS tenha se dado, em primeiro lugar, em razão da necessidade de sobrevivência e de representar em relação aos trabalhos anteriores (empacotadora, balconista, auxiliar de serviços gerais, secretária, garçonete, telefonista, entre outros) maior estabilidade no emprego, foi no envolvimento com o próprio trabalho que as agentes passaram a perceber o sentido útil do que fazem e receberam o reconhecimento da população. ${ }^{12}$ Acrescente-se, como destacam Simões Barbosa e colaboradores (2012), que a solidariedade com a comunidade é vista em nossa sociedade como uma característica do feminino, e o trabalho das ACSs, calcado na valorização desse sentimento, contribui para que essas trabalhadoras permaneçam no emprego mesmo em condições precárias.

Além disso, a implementação do PSF trazia a perspectiva de mudança no modelo de atenção, sobressaindo a importância do trabalho das agentes para possibilitar a integralidade na saúde. Nota-se que, quando elas começaram a atuar como ACSs, a perspectiva de mudança nas condições de vida da população dava outro sentido ao trabalho que realizavam.

Eles mostraram pra gente um lado bonito, o lado belo, como se fosse um sonho implantado na gente. Assim é a coisa certa, deve acontecer assim (ACS 16). 
De fato, o trabalho das agentes foi fundamental para a implementação do PSF, pois todo o mapeamento das áreas, bem como o cadastramento das famílias, era de atribuição das ACSs. Tal processo de mapeamento e cadastramento foi ajudando as agentes a conhecerem melhor a comunidade e a se identificaram pelo e com o trabalho. Desta forma, sublinha-se que o território da saúde não diz respeito somente aos aspectos físicos ou geográficos, "mas é de inscrição de sentidos no trabalho, por meio do trabalho, para o trabalho" (Ceccim apud Gondim e Monken, 2009).

Fomos nós que corremos atrás do lugar. A gente fez o concurso pela Prefeitura, (...) mas nós que começamos a correr atrás do lugar para ficar, nós começamos a arrumar as cadeiras e todas as coisas para as primeiras reuniões. (...) O Gat (Grupo de Apoio Técnico) levava o papel, sentávamos no chão e começávamos a desenhar a comunidade. Fazia o mapa e aquilo foi despertando ainda mais a gente para poder ver que a situação era ruim... (ACS 11).

Em que pese uma visão romantizada sobre a constituição do PSF pelas agentes, nota-se um envolvimento com o projeto de mudança no modelo de atenção. Rummert (2000, p. 36) ajuda a compreender esse fazer-se das ACSs, ao esclarecer o que entende por identidade: “um sentimento de pertença - que pode ser organicamente percebido ou atribuído do exterior - a um determinado grupo e a um determinado projeto". Acrescenta que esse sentimento de pertença só se torna hegemônico quando há uma possibilidade, ainda que esta possa ser ilusória, de sua concretização, e para tanto se faz necessário um investimento emocional e afetivo pelo indivíduo ou pelo grupo.

Você acaba se envolvendo, porque eu, sinceramente, não conhecia a minha comunidade antes de ser ACS. Minha trajetória era só a minha rua (...). O outro lado eu não conhecia (...). E você trabalhando começa a conhecer as pessoas. Eu até falo que, hoje em dia, se eu soubesse que iria me identificar tanto com esse trabalho, eu teria feito outra carreira na faculdade (ACS 7).

Em grande medida, esse investimento emocional e profissional se dava no contato com os moradores, nas visitas domiciliares e nos grupos educativos que realizavam com a população. Como no momento da implantação as equipes do PSF ainda não estavam estruturadas, o trabalho educativo com os moradores era o que de concreto se realizava na política. A equipe do PSF é, atualmente, composta por um médico generalista, um enfermeiro, um auxiliar de enfermagem e quatro a seis agentes. Porém, nas entrevistas, as ACSs relataram grande dificuldade na fixação de médicos no programa, o que prejudica o estabelecimento de vínculos desses profissionais com a comunidade. 
Diferentemente dos médicos e dos enfermeiros, cujo contato com os usuários se dá dentro do expediente de trabalho, para as ACSs essa relação se estende além do seu horário de trabalho, envolvendo os espaços públicos que frequentam em momentos de folga. Acrescente-se que, em razão de conhecerem as dificuldades vivenciadas cotidianamente por essas famílias, sentem-se implicadas com os problemas que afetam os usuários. Esse estreito vínculo das agentes com a população atendida, que não se fez acompanhar de uma aproximação semelhante dos demais membros da equipe do PSF, acabou por restringir a essas profissionais o contato mais humanizado com os usuários.

Ao investigar o trabalho das ACSs no momento em que o PSF ganha corpo no município do Rio de Janeiro, Morosini (2001, p. 44) questiona como ou onde estaria localizado o trabalho dos agentes nos serviços de saúde e conclui que "O agente de saúde é aquele que não se vê no posto, é o que passa por lá que leva as pessoas para lá. É o que identifica, encaminha, orienta e acompanha" (grifos nossos).

Passada mais de uma década da implementação do programa, observa-se uma mudança no trabalho das agentes, pois o protagonismo dessas trabalhadoras nas comunidades, conforme assinalado por Morosini (2001), já não é tão evidente, o que coloca em xeque o projeto inicial.

\section{O fazer-se ACS ante a reforma da atenção primária}

Em 2009, no município do Rio de Janeiro, há uma expansão do PSF sob novos marcos. O espaço de trabalho passa a se organizar nas clínicas de saúde da família, bem como o gerenciamento dos serviços e as ações de atenção primária se dão via OSSs (Carneiro, 2013). Andreazzi e Bravo (2014) esclarecem que a adoção desse modelo de administração deu-se por meio da lei municipal das OSSs (lei n. 5.056), sancionada em maio de 2009. As autoras indicam o aumento desse tipo de gestão no município, salientando que em 2011 foram qualificadas como OSSs 37 entidades 'sem fins lucrativos', e 21 delas eram na área da saúde.

Essas mudanças passam a ser denominadas pela Secretaria Municipal de Saúde e Defesa Civil (SMSDC) como reforma da atenção primária, que tem como objetivo a expansão da cobertura para $70 \%$ da população até 2016 . Fonseca (2013) esclarece que a adoção do modelo de OSS corresponde à terceirização da gerência das unidades por entidades privadas não lucrativas. Por meio de um contrato de gestão, estabelecem-se as metas que deverão ser alcançadas, vinculando o alcance a incentivos financeiros. O ingresso das OSSs foi correlato a uma mudança na gestão do trabalho, com o investimento em tecnologia da informação, o foco em resultados e a introdução de elementos de competição. 
Vale salientar que os vínculos trabalhistas das agentes antes da entrada das OSSs se davam por meio de várias organizações não governamentais (ONGs). Essa pulverização das relações trabalhistas entre as ONGs se traduzia na diferenciação entre os salários, bem como nos seus benefícios indiretos (vale-transporte, tíquete-alimentação, adicional por insalubridade, salário-família etc.). Era comum haver atrasos no pagamento, ruptura de contrato sem os direitos devidos, entre outros problemas. ${ }^{13}$

Pode-se constatar que desde o início da implantação do PSF no município o trabalho das ACSs já se constituía como um trabalho precarizado. O diferencial que marca a entrada das OSSs é a intensificação das lógicas de gestão apregoadas no setor privado, estimulando a concorrência principalmente entre as unidades de saúde e seus trabalhadores, a produção por meta, as parcerias com o setor privado, a preocupação exacerbada com os indicadores etc.

Essa mudança na organização dos serviços teve forte impacto sobre o trabalho realizado pelas agentes entrevistadas. As ACSs se constituíram e foram constituídas pela política, tendo como o principal diferencial do seu trabalho o comprometimento e a ligação com os usuários. A despeito dos baixos salários, da sua relação precária com o SUS, era o reconhecimento da população pelo que faziam o que dava coerência e sentido para o seu fazer. Como se procurou destacar, esses elementos estavam imbricados com o papel do cuidado realizado pelas mulheres na esfera doméstica.

A reestruturação do trabalho nas clínicas de saúde da família foi significativa de uma fragmentação do trabalho das ACSs, pois as atividades realizadas tornaram-se mais normatizadas, havendo um parcelamento das suas atribuições, significativas de um trabalho simplificado (Fonseca, 2013).

A parcelarização das atividades e o trabalho gestado por metas têm forte impacto sobre as atividades nas quais as ACSs tinham mais autonomia: as visitas domiciliares e os grupos de promoção à saúde. A necessidade do cumprimento do número de visitas domiciliares (VDs) acabou por restringir o tempo da visita, bem como a visão das agentes sobre o trabalho.

Nesse contexto, as VDs deixam de ser um espaço de interação com os usuários, transformando-se em visitas funcionais guiadas pelos interesses dos formuladores da política. Acrescente-se que o aumento da demanda, aliado à necessidade de se atingirem as metas impostas, limita uma escuta de qualidade junto à população. Assim, todo um conhecimento tácito, como saber ouvir, ter sensibilidade e jogo de cintura, passa a não ser valorizado.

Eu não vou marcar aquelas duas porque não é prioridade. Não estão sentindo nada. E dói pensar assim. Porque a gente é meio idealista, que é antigo (...). Porque a gente deve sempre preservar a boa saúde da pessoa. Que não se resume em só não estar sentindo nada. Então, eu não vou marcar o seu nome aí. Chega um dia que 
você vai se tornar prioridade. [Questiona-se] Cadê aquela pessoa que eu me preparei para ser? (ACS 2, grifos nossos).

Outro aspecto de atribuição do trabalho das agentes eram os grupos de promoção de saúde. Esse era um espaço de regência do agente, que vem desaparecendo atualmente. 14 Nesse sentido, como avalia uma entrevistada:

Grupos de convivência, que na verdade é um método de promoção, que a gente tem, que é da governabilidade do agente e acabou sendo tirado (...), para entrar o turno de burocracia que é o prontuário eletrônico, que é o que atualmente faz diferença (ACS 5).

Na compreensão das ACSs, o trabalho na clínica passa a ser mais individualizado. Assim, se antes as orientações ocorriam, fundamentalmente, nos grupos ou nas VDs, atualmente, quando existem, são dadas na própria clínica da família. Essa mudança no espaço é significativa de uma perda do seu saber, pois a gestante que necessita de atendimento, por exemplo, já não diz respeito a uma pessoa da sua área de atuação que conhecia a família, as condições de vida e a história. A gestante passa a ser da clínica, perdendo o vínculo mais direto com a agente. Vale a pena acrescentar que, muitas vezes, as famílias dentro dos serviços eram reconhecidas pela relação que estabeleciam com essas trabalhadoras. Assim, não raro o usuário era identificado pela ligação com as agentes. "Quando você pega uma gestante, não é a minha gestante, é a gestante da clínica" (ACS 7).

Se no início do programa, no município, o mapeamento das áreas era feito manualmente pelos ACSs e incluía não só o cadastramento das famílias, mas também toda uma percepção do entorno, com os novos sistemas de informação (Vitacare, MedicineOne, entre outros) esse saber passa a ser gerenciado pelos formuladores da política, estabelecendo quais dados serão prioritários.

Como bem analisa Fonseca (2013), o sistema de informação interfere nos processos de trabalho das agentes e delimita os aspectos para os quais deve convergir a atenção do profissional, a organização do seu trabalho e a sua finalidade, que passa a ser a digitação das informações. Nesse quadro, a compreensão mais ampla sobre o trabalho é estabelecida em um espaço de poder, em que não há intervenção dos trabalhadores.

(...) não generalizar, porque a minha comunidade é na zona norte, a gente tem todo um acesso diferente de quem mora lá na zona oeste. Temos dificuldades e situações diferentes e temos (também) facilidades diferentes. Então, quem devia discutir isso é quem está lá na ponta, pelo menos no meu ver. Só que não é feito dessa forma, e vem um pacote fechado (ACS 5). 
Nesse contexto, o reconhecimento da área, bem como a percepção dos agentes sobre aquele território, deixa de ser valorizado e passa a ser regido mais fortemente pela gerência. Não se quer com isso negligenciar a importância da informação para as políticas de saúde, mas sim criticar a ênfase dada na reforma da atenção primária ao alcance de metas, em detrimento da qualidade nos serviços.

Porque agora você tem todo um sistema de informação que você tem que alimentar. Então você deixa de ser aquela pessoa que está lá no campo, observando todo o entorno, porque você tem que estar na unidade alimentando (ACS 2).

Diante da produção por meta e da correlata preocupação com os números, acaba-se por desumanizar os parcos espaços onde havia interação com a população.

Essas mudanças acabam gerando nas próprias ACSs uma cisão entre os profissionais antigos e os novos, na medida em que, com os novos processos de trabalho, alteram-se as habilidades que davam sustentação ao seu trabalho. As agentes novas acabam por personificar a desvalorização do fazer das antigas, em um embate que se dá no cotidiano do trabalho. Se antes, como assinala Morosini (2001), o que diferenciava o agente era não ser visto no posto de saúde, com essas mudanças essa ausência passa a ser compreendida como uma falta de comprometimento com o serviço. Como esclarece uma das entrevistadas:

\footnotetext{
Uma menina falou assim: "Engraçado, esses ACSs antigos não trabalham, eu não os vejo na clínica." Eu respondi: "Olha, exatamente, eu não fico mais na clínica, eu trabalho na rua." Eles achavam que se eu não ficava na clínica, eu não estava trabalhando (ACS 4).
}

Fonseca (2013), ao pesquisar uma clínica da família onde a maioria das ACSs era nova, constatou que as agentes não compreendiam o trabalho como desgastante. A autora analisa que essa visão está relacionada ao parcelamento das atividades - pois a divisão destas em tarefas simplificadas leva a uma diminuição da intensidade do trabalho. As ACSs entrevistadas no escopo desta pesquisa se ressentem do trabalho atual, pois vivenciaram intensamente a perda do sentido com o qual elas vinham, a duras penas, construindo a sua identidade profissional. Acabam por perder com as 'novas' formas de gestão o diferencial que dava significado ao seu trabalho, ou seja, a integração com as pessoas e o reconhecimento que conquistaram nesse processo. Acrescente-se que a divisão entre novos e antigos dentro da categoria acaba por enfraquecer ainda mais o processo de luta pela sua efetiva profissionalização. 
No município do Rio de Janeiro, a organização desses trabalhadores tem avançado lentamente, devido sobretudo à dificuldade de mobilização da categoria. Em 2012, a Associação dos Agentes Comunitários de Saúde logrou se estabelecer como sindicato, formando atualmente o Sindicato dos Agentes Comunitários de Saúde do Rio de Janeiro.

Como também analisaram Simões Barbosa e colaboradores (2012), embora constate-se a insatisfação das agentes quanto aos baixos salários, à falta de reconhecimento pelo Estado e aos próprios serviços de saúde - o que pode ser significativo de maior consciência coletiva sobre a exploração no trabalho -, essa insatisfação não se expressa na participação no sindicato.

Em que se pesem as dificuldades da classe trabalhadora em fazer frente às políticas neoliberais em curso, as mulheres ACSs esbarram ainda em outros entraves que as impedem de maior articulação com a categoria. Entre eles, destacam-se: a circunscrição do seu trabalho-vida a um local bem delimitado de atuação que acaba encapsulando-as no cotidiano, tornando difícil a percepção do sentido mais amplo do seu trabalho; a jornada de trabalho, que se estende para os horários livres; o cuidado com os filhos e os afazeres domésticos; e ainda os trabalhos informais que realizam como forma de complementação de renda. Evidenciam-se, portanto, barreiras de gênero que dificultam ainda mais a organização política dessas trabalhadoras (Simões Barbosa et al., 2012).

\section{Considerações finais}

Buscou-se neste artigo enfatizar o fazer-se das agentes na institucionalização do seu trabalho, a fim de se lançar luz sobre um aspecto da constituição dessas trabalhadoras que corria o risco de ser esquecido. O esforço foi de retomar as experiências dessas mulheres que tiveram efetiva participação na implantação do PSF no Rio de Janeiro e construir, no dizer de Thompson (2012, p. 185), uma "história vista de baixo".

As ACSs do município do Rio de Janeiro, durante mais de uma década, lutaram para salvaguardar o que dava singularidade a sua profissão: o tão alardeado elo com a comunidade. Assim, quando há um afastamento do que as diferenciava do restante dos profissionais do PSF e quando o engajamento com a população passa a ser secundário, passa-se a exigir das agentes outras atribuições que já não pressupõem habilidades culturalmente formadas como atributo feminino. Não por acaso, percebe-se a inserção, gradativa, de homens como ACSs, o que pode ser significativo de uma "transição de gênero", conceito cunhado por Giffin (2002) para sinalizar a passagem de formas culturais atribuídas a um determinado sexo que sofrem transformações na história. Em face da contração cada vez mais acirrada do mercado de trabalho, o tra- 
balho como ACS passa a ser uma ocupação interessante não só para mulheres, mas também para homens em busca de emprego, passando a se igualar aos numerosos trabalhos desqualificados que fazem parte da trajetória de vida da classe trabalhadora.

Acredita-se que a dimensão relacional do trabalho das agentes se constituiu em uma ferramenta importante para tornar visível o seu trabalho, contendo um ideário de maior participação da população nas políticas de saúde. O que se esperava era que essas habilidades, ao serem valorizadas, deixassem de ser entendidas como inatas à natureza feminina e, como tal, tivessem um reconhecimento pontual e se expressassem também na relação contratual, em melhores condições de trabalho, no salário e na formação. Ao que tudo indica, a dimensão do trabalho das ACSs - o qual continha maior potencial de se tornar mais complexo - é limitada com a nova reestruturação do trabalho, pois este é reduzido a tarefas simplificadas que diminuem ainda mais a autonomia das agentes.

\section{Colaboradores}

Anna Violeta Ribeiro Durão e Clarissa Alves Fernandes de Menezes participaram de todas as etapas da pesquisa. Ambas trabalharam na concepção e redação do artigo. As autoras declaram que não há conflitos de interesse.

Resumen Este artículo es el resultado de una investigación que tuvo por objetivo analizar la institucionalización del trabajo de las agentes comunitarias de salud en el municipio de Río de Janeiro, capital del estado de mismo nombre, Brasil. Se evaluó cómo determinada perspectiva de género, presente en la política de calificación de estas trabajadoras, viene afectando la constitución se su profesión. Participaron en el estudio 167 agentes entre los años 2011 y 2013. En primer lugar, se presenta la perspectiva de género existente en las políticas del Estado dirigidas hacia las agentes. Luego, se recupera la experiencia de trabajo de estas trabajadoras en la implementación del Programa Salud de la Familia en el municipio y su relación con habilidades consideradas innatas a la condición femenina. Posteriormente, se analizó cómo la reforma de la atención primaria, realizada por la Secretaría Municipal de Salud y Defensa Civil en el 2009, viene afectando el proceso laboral de las agentes. Se constató que, con las nuevas formas de gestión adoptadas, las agentes se han distanciado de las comunidades atendidas, perdiendo, de esta manera, el diferencial que atribuía significado y reconocimiento a su trabajo.

Palabras clave agentes comunitarias de salud; género; trabajo. 


\section{Dedicatória}

Para Regina Neri, in memoriam.

\section{Notas}

1 Fundação Oswaldo Cruz, Escola Politécnica de Saúde Joaquim Venâncio, Laboratório de Educação Profissional em Atenção à Saúde.

<violetadurao@fiocruz.br>

Correspondência: Fundação Oswaldo Cruz, Escola Politécnica de Saúde Joaquim Venâncio, sala 312, Avenida Brasil, 4.365, Manguinhos, CEP 21040-360, Rio de Janeiro, Rio de Janeiro, Brasil.

2 Universidade do Estado do Rio de Janeiro, Centro de Ciências Sociais, Faculdade de Serviço Social.

$<$ clarissaafm@gmail.com>

3 Entende-se o conceito de qualificação no mesmo sentido dado por Machado (1996) e Ramos (2002), quando ressaltam a sua configuração como processo e produto de determinada relação social engendrada pelo próprio trabalho.

$4 \mathrm{O}$ resultado dessa pesquisa está disponível no livro Trabalhadores técnicos da saúde: aspectos da qualificação profissional no SUS (Morosini et al., 2013), no qual também se encontra uma primeira análise dos resultados do grupo das ACSs, no artigo "Qualificação e gênero no trabalho das agentes comunitárias de saúde."

5 Em 1997, o Programa Saúde da Família passa a ser entendido como uma estratégia voltada para a remodelação do sistema de atenção à saúde em seu conjunto, passando, por isso mesmo, a ser denominado Estratégia Saúde da Família (ESF).

${ }^{6}$ Entende-se o Estado no sentido formulado por Gramsci, para o qual "Estado = sociedade política + sociedade civil, isto é, hegemonia couraçada de coerção" (Gramsci, 2001, p. 244). O Estado em sentido estrito refere-se à sociedade política que corresponde aos mecanismos pelo qual a classe dominante impõe coercitivamente a sua dominação. Já a sociedade civil se configura como o espaço de luta de classes, em que os diversos sujeitos políticos coletivos, por meio de seus aparelhos privados de hegemonia, disputam a direção política e cultural das formações sociais (Montaño e Durigueto, 2010; Neves, 2005; Fontes, 2006).

7 A partir de 1992, o programa passa a ser denominado Programa de Agentes Comunitários de Saúde (PACS).

8 Sobre o uso ideológico do conceito de comunidade no campo da saúde, ver Durão, Morosini e Carvalho (2011).

9 Atualmente, o nível de escolaridade exigido para o ingresso como ACS é o ensino fundamental completo. Para a conclusão do curso técnico, requer-se também o término do ensino médio (lei n. 11.350/2006). 
10 Marx (2004) distingue trabalho vivo de trabalho morto. Por trabalho vivo, o autor entende a força de trabalho posta em movimento, enquanto trabalho morto refere-se ao trabalho anterior objetivado em determinado produto. Como no trabalho em saúde não é possível separar o produtor do seu produto, este se torna mais dependente do trabalho vivo. Kuenzer (2004) destaca que essa peculiaridade do trabalho em saúde limita, de certo modo, a lógica capitalista, que necessita convencer - seja pela força, seja pela persuasão - o trabalhador a ser artífice da sua própria exploração.

$11 \mathrm{O}$ trabalho de cuidado (care work) é uma atividade profissional em expansão em escala internacional, que surge, entre outras causas, em razão do envelhecimento da população, que requer soluções para o cuidado de idosos dependentes, e da entrada maciça das mulheres no mercado de trabalho (Hirata e Guimarães, 2012).

12 Para Marx, o trabalho no capitalismo tem uma dupla dimensão: produz relações sociais alienantes ao mesmo tempo que produz o próprio homem. Assim, o homem realiza trabalho útil quando satisfaz as suas necessidades de vida em determinada atividade (Marx, 2004; Kuenzer, 2004).

13 A questão dos vínculos salariais dos ACSs ganhou destaque no seminário "Luta pelo reconhecimento e pela regulação do trabalho do ACS no contexto nacional e da legislação vigente", realizado em 2009 pela Escola Politécnica de Saúde Joaquim Venâncio juntamente com a Associação Municipal de Agentes Comunitários de Saúde do Rio de Janeiro (AMACS). O seminário tinha como objetivo contribuir para a elaboração de estratégias de fortalecimento do movimento dos ACSs do município do Rio de Janeiro.

14 Fonseca (2013) destaca que o indicador dos grupos educativos está atrelado ao pagamento de desempenho, que orienta o contrato de gestão com as OSSs. Porém, esse indicador só é válido quando conduzido por profissionais de nível superior e técnico, o que exclui os ACSs.

\section{Referências}

ANDREAZZI, Maria F. S.; BRAVO, Maria I. S. Privatização da gestão e organizações sócias na atenção à saúde. Trabalho, Educação e Saúde, Rio de Janeiro, v. 12, n. 3, p. 499518, dez 2014.

BOURDIEU, Pierre. A dominação masculina. Rio de Janeiro: Betrand Brasil, 2010.

CARNEIRO, Carla C. G. A inserção do agente comunitário de saúde no município do Rio de Janeiro. 125f. Dissertação (Mestrado em Saú- de Pública) - Escola Nacional de Saúde Pública Sergio Arouca, Fundação Oswaldo Cruz, Rio de Janeiro, 2013.

DURÃO, Anna V.; MOROSINI, Márcia V. G. C.; CARVALHO, Valéria. O ACS e o conceito de comunidade na configuração de sua qualificação. In: VIEIRA, Monica; DURÃO, Anna V.; LOPES, Márcia (orgs.). Para além da comunidade: o trabalho e a qualificação do agente comunitário de saúde. Rio de Janeiro: EPSJV, 2011. p. 119-160. 
DURÃo, Anna V. et al. Qualificação e gênero no trabalho das agentes comunitárias de saúde. In: MOROSINI, Márcia V. G. C. et al. (orgs.). Trabalhadores técnicos da saúde: aspectos da qualificação profissional. Rio de Janeiro: EPSJV, 2013. p. 421-441.

FARAH, Marta F. S. Gênero e políticas públicas. Estudos Feministas, Florianópolis, v. 12, n. 1, p. 47-71, jan.-abr. 2004. Disponível em: <www.scielo.br/pdf/ref/v12nl/ 21692>. Acesso em: 23 ago. 2013.

FONSECA, Angélica F. O trabalho do agente comunitário: implicações da avaliação e da supervisão na educação em saúde. 233f. Tese (Doutorado em Saúde Pública) - Escola Nacional de Saúde Pública Sergio Arouca, Fundação Oswaldo Cruz, Rio de Janeiro, 2013.

FONTES, Virgínia. Sociedade civil no Brasil contemporâneo: lutas sociais e luta teórica. In: LIMA, Julio C. F.; NEVES, Lúcia M. W. (orgs.). Fundamentos da educação escolar do Brasil contemporâneo. Rio de Janeiro: Editora Fiocruz, 2006. p. 201-239.

GEORGES, Isabel; SANTOS, Yumi G. dos. Care e políticas públicas: o caso das "agentes comunitárias de saúde" e das "agentes de proteção social". In: HIRATA, Helena; GUIMARÃES, Nadya. A. (orgs.). Cuidado e cuidadoras: as várias facetas do trabalho do care. São Paulo: Atlas, 2012. p. 166-181.

GIFFIN, Karen. Pobreza, desigualdade e equidade em saúde: considerações a partir de uma perspectiva de gênero transversal. Cadernos de Saúde Pública, Rio de Janeiro, v. 18, p. 103-112, 2002. Suplemento.

GONDIM, Gracia M. M.; MONKEN, Maurício. Territorialização em saúde. In: PEREIRA, Isabel B.; LIMA, Julio C. F. (orgs.). Dicionário da educação profissional em saúde. Rio de Janeiro: EPSJV, 2009, p. 393-399.

GRASMCI, Antonio. Cadernos do Cárcere. 3. ed. Rio de Janeiro: Civilização Brasileira, 2001. (Volume 2; os intelectuais; o princípio educativo; o jornalismo).
HIRATA, Helena; GUIMARÃES, Nadya A. Introdução. In: HIRATA, Helena; GUIMARÃES, Nadya. C. Cuidado e cuidadoras: as várias facetas do trabalho do care. São Paulo: Atlas, 2012. p. 1-11.

HIRATA, Helena; KERGOAT, Danièle. Novas configurações da divisão social do trabalho. Cadernos de Pesquisas, São Paulo, v. 37, n. 132, p. 595-609, set.-dez. 2007. Disponível em: $<$ www.scielo.br/pdf/cp/v37n132/a0537132. pdf>. Acesso em: 5 ago. 2013.

KUENZER, Acácia Z. Sob a reestruturação produtiva, enfermeiros, professores e montadores de automóveis se encontram no sofrimento do trabalho. Trabalho, Educação e Saúde, Rio de Janeiro, v. 2, n. 1, p.127-135, 2004.

MACHADO, Lucília. Qualificação do trabalho e relações sociais. In: FIDALGO, Fernando (org.). Gestão do trabalho e formação dos trabalhadores. Belo Horizonte: Movimento de Cultura Marxista, 1996. p. 13-40.

MARX, Karl. O capital: crítica da economia política. Livro 1. Rio de Janeiro: Civilização Brasileira, 2004.

MATTOS, Marcelo. B. E. P. Thompson e a tradição de crítica ativa do materialismo histórico. Rio de Janeiro: Editora da UFRJ, 2012.

MENEZES, Clarissa A. F. Trabalhadeira, mulher e guerreira: o (precário) trabalho das agentes comunitárias de saúde. 127f. Dissertação (Mestrado em Saúde Coletiva.) - Instituto de Estudos em Saúde Coletiva, Universidade Federal do Rio de Janeiro, Rio de Janeiro, 2011

MOLINIER, Pascale. Ética e trabalho do care. In: HIRATA, Helena; GUIMARÃES, Nadya A. (orgs.). Cuidado e cuidadoras: as várias facetas do trabalho do care. São Paulo: Atlas, 2012. p. 29-43.

MONTAÑO, Carlos. Terceiro setor e questão social: crítica ao padrão emergente de intervenção social. São Paulo: Cortez, 2003. 
MONTAÑO, Carlos; DURIGUETO, Maria L. Estado, classe e movimento social. São Paulo: Cortez, 2010.

MOROSINI, Márcia V. G. C. O agente comunitário de saúde no marco da Estratégia Saúde da Família no município do Rio de Janeiro: desafios à formação em saúde. Pesquisa do Programa de Aperfeiçoamento do Ensino Técnico. Relatório. Rio de Janeiro: EPSJV/Fiocruz, 2001. Mimeografado.

MOROSINI, Márcia V. G. C. Educação e trabalho em disputa no SUS: a política de formação dos agentes comunitários de saúde. Rio de Janeiro: EPSJV, 2010.

MOROSINI, Márcia V. G. C. et al. Trabalhadores técnicos em saúde: aspectos da qualificação profissional no SUS. Rio de Janeiro, EPSJV, 2013.

NEVES, Lúcia M. W. A sociedade civil como espaço estratégico de difusão da nova pedagogia da hegemonia. In: NEVES, Lúcia M. W. (org.). Pedagogia da hegemonia: estratégias do capital para educar o consenso. Rio de Janeiro: Xamã, 2005. p. 85-125.

NOGUEIRA, Roberto P.; SILVA, Frederico B.; RAMOS, Zuleide. V. A vinculação institucional de um trabalhador sui generis: o agente comunitário de saúde. Rio de Janeiro: Ipea, 2000. Disponível em: <www.ipea.gov. br/agencia/images/stories/PDFs/TDs/td_ 0735.pdf $>$. Acesso em: 5 set. 2012. (Texto para Discussão; n. 735).

RAMOS, Marise. A pedagogia das competências: autonomia ou adaptação? São Paulo: Cortez, 2002.

RIZZOTTO, Maria L. F. O Banco Mundial e as politicas de saúde no Brasil nos anos 90: um projeto de desmonte do SUS. 275f. Tese (Doutorado em Saúde Coletiva.) - Faculdade de Ciências Médicas, Universidade Estadual de Campinas, Campinas, 2000.

RUMMERT, Sonia M. Educação e identidade dos trabalhadores: as concepções do capi- tal e do trabalho. São Paulo: Xamã; Niterói: Intertexto, 2000.

RUMMERT, Sonia M. Desafios teóricos e metodológicos da educação de jovens e adultos trabalhadores. In: CANÁRIO, Rui; RUMMERT, Sonia Maria (orgs.). Mundos do trabalho e aprendizagem. Lisboa: Educa, 2009, p. 19-42.

SCOTT, Parry. As famílias que os programas de saúde pública constroem no Brasil. In: NASCIMENTO, Pedro; RIOS, Luis F. (orgs.). Gênero, saúde e práticas profissionais. Recife, Editora da UFPE, 2011, p. 13-49.

SERRA, Carlos G. Garantia de acesso à atenção básica e continuidade de cuidados como estratégia para consolidação da integralidade no SUS: uma análise sobre os processos de implantação do PSF, construção de sistemas de referência e regionalização assistencial no estado do Rio de Janeiro. 203f. Tese (Doutorado em Saúde Coletiva.) - Instituto de Medicina Social, Universidade do Estado do Rio de Janeiro, 2003.

SIMÕES BARBOSA, Regina H. Mulheres, reprodução e Aids: as tramas da ideologia na assistência à saúde de gestantes HIV+. $310 \mathrm{f}$. Tese (Doutorado em. Saúde Pública) - Escola Nacional de Saúde Pública Sergio Arouca, Fundação Oswaldo Cruz, Rio de Janeiro, 2001.

SIMÕES BARBOSA, Regina H. et al. Gênero e trabalho em saúde: um olhar crítico sobre o trabalho de agentes comunitárias/os de saúde. Interface: Comunicação, Saúde, Educação, Botucatu, v. 16, n. 42, p. 751-765, 2012.

THOMPSON, Edward P. A miséria da teoria ou um planetário de erros. Rio de Janeiro: Zahar, 1981.

THOMPSON, Edward P. A formação da classe operária inglesa: a árvore da liberdade. v. 1. Rio de Janeiro: Paz e Terra, 1987.

THOMPSON, Edward P. A história vista de baixo. In: NEGRO, Antonio L.; SILVA, Sérgio (orgs.). THOMPSON, E. P.: as peculiaridades dos ingleses e outros artigos. São Paulo: Unicamp, 2001, p. 185-201. 
TOMÁZ, José B. C. O agente comunitário de saúde não deve ser um 'super-herói'. Interface: Comunicação, Saúde, Educação, Botucatu, v. 6, n. 10, p. 84-88, fev. 2002.

Recebido em 26/03/2014

Aprovado em 30/01/2015 